\title{
HIGH-TECH START-UPS IN JAPAN: COGENT LABS, AI-OCR SOLUTIONS FOR AUTOMATED BUSINESS PROCESS OUTSOURCING
}

\author{
Jorge Calvo \\ GLOBIS University Graduate School of Management \\ Tokyo, Japan \\ jorge.calvo@globis.ac.jp
}

\begin{abstract}
This business research case introduces Cogent Labs, a Japanese high-tech start-up that provides AI-driven technologies, is making the critical transition from an entrepreneur-driven to a mature management-run organization, the company's business context and technology development. That requires to harmonize the entrepreneurial and managerial capacity, by a collaborative approach integrating cross-functional product teams. The high-tech start-up has demonstrated ability to overcome the transitional stage of the first entrepreneurship to stability and sustainability through the management, while at the same time keeping innovation by adding Natural Language Processing and Times-Series developments, and creativity; rapidly developing new products. The business case demonstrates that in the start-up to managerial transition of a high-tech start-up the key success factor lies in the motivation and coordination of the different professional cultures -scientific and engineering- that should collaborate in the AI research and fast development of viable products. The method is based on interviews conducted with key executives and a strategic analysis of the firm and its rapidly evolving context in terms of artificial intelligence (AI) and deep learning. The start-up company develops AI-based applications like Tegaki AI, supporting their initial clients from the financial sector in the incremental automation of business processes, based on AIand Internet of Things (IoT)-driven business processes. Tegaki AI triggers non-strategic business decisions through optical character recognition (OCR) and optical handwriting recognition (OHR) algorithms that show 99.2\% accuracy. This business case describes the context of entrepreneurship ecosystems in Japan and the economic emergence of business smartization solutions through the new AI paradigm and OHR.
\end{abstract}

KEYWORDS: Entrepreneurship, Start-up, Artificial Intelligence, Business Process, Optical Handwriting Recognition, Optical Character Recognition, Machine Learning, Natural Language Processing

JEL CLASSIFICATION: L21, L25, L26. M13, M15

DOI: $10.2478 / \mathrm{IJEK}-2018-0011$

Received: $30^{\text {th }}$ March, 2018

1st Revision: $25^{\text {th }}$ June, 2018

Accepted: $20^{\text {th }}$ August, 2018

Reference: Calvo, J. (2018). High-tech start-ups in Japan: Cogent Labs, AI-OCR solutions for automated business process outsourcing. International Journal of Entrepreneurial Knowledge, 6(2), 12-31. doi: 10.2478/IJEK-2018-0011

\section{INTRODUCTION}

Founded in 2014 by Jun Inuma and Eric Whiteway, current executive directors, the company is located in Tokyo and has a capital of 1.472 billion yen ( $\$ 13$ million) (including reserves). The mission of Cogent Labs "is to research and develop cutting-edge artificial intelligence in order to solve the previously impossible. Through real-world applications of our technology we aim to bring meaningful and transformative impact to society with the ultimate goal of enhancing the overall quality of life." (Cogent Labs Inc., 2017). Jun Inuma, co-founder and CEO at Cogent Labs, stated in an interview in July 2017:

\footnotetext{
"When I was working for a cloud computing company [Salesforce.com], I had large doubts in my mind towards the industry and market which had room for improvement and innovation. While thinking about how technology may support measures to resolve the primary industry sector issue in the Japanese market, and the issue of future decrease in the working population, as well as development of the world economy, I strongly felt the potential of artificial
} 
intelligence and founded Cogent Labs." ... "Cogent Labs aims at improving market gaps in Artificial Intelligence by providing real-time solution centric towards favouring Japanese Market Structure. Cogent Labs intends to increase the application of Artificial Intelligence to solve societal problems and improve the quality of life-" (Cogent Labs Inc., 2017; Inuma, J. \& Malkin, 2017).

According to Cogent Labs, artificial intelligence is a determinant method of solving complex problems, as Japanese handwriting includes Kana (Hiraganaand Katakana) and Kanji (Chinese) alphabets, with a total of over 50,000 characters (Sasanuma \& Fujimura, 1971). As of 2010, Japanese primary and secondary school students are required to learn 2,136 basic Kanji characters. As an example, Wakahara and Odaka (1997) presented a distortion-tolerant online cursive Kanji character recognition software for 2,980 Kanji character categories, obtaining a recognition rate of 96.0 percent.

According to Amin (n.d.), AI algorithms develop an automated approach whereby experts can obtain information extracted from the document via AI-based in-depth learning protocols. Cogent Labs uses artificial intelligence to create proprietary algorithms essential in solving problems in handwriting recognition, optical character recognition and improving business processes (Cogent Labs Inc., 2017).

Using multiple neural network mechanisms, AI engines can observe the user's stylus patterns and recognize verbs, characters and phrases, and also writing behaviours. The importance of this research is that it is a vital impetus to ensuring real-time handwriting data processing signature verification during credit card transactions in supermarkets, subways and retail store checkout points (Kessentini, Burger, \& Paquet, 2010). Users can sign via Personal Digital Agendas (PDA) and Tablet Computers to authenticate their signature or write application forms for further scanning, and guarantee automated business processes that previously required human verification. AI is vital to ensuring automation of the handwriting process to make it adequately fit real-world instances (Navigli \& Ponzetto, 1999). A strong determinant for the rapid growth of Cogent Labs is the presence of dedicated information experts and data scientist, combined with advanced business expertise and excellent academic skills, from different nationalities working together in Tokyo close to the market and clients in order to better understand their needs, in a co-creation product development model. Jun Inuma defined the competitive advantage at Cogent Labs as:

\footnotetext{
"What is unique about and also a strong point of Cogent Labs is that its team is comprised of members with strong business skills based on high quality academic knowledge and experience. By adapting sound knowledge and its technology to business issues and social problems which no one has been able to resolve, our team is aiming to provide unprecedented innovation. The team also has global diversity, and we are developing a system to rapidly develop by expanding into world markets." (Inuma, J. \& Malkin, 2017).
}

\section{SCOPE AND OBJECTIVES}

According Kuratko (2017) "managing entrepreneurial growth may be the most critical tactic for the future success of a business enterprise". The challenge lies in managing harmoniously the entrepreneurial and managerial capacity, accompanying dynamic and changing factors for transitioning from entrepreneurial approach to managerial. What requires the entrepreneur to possess at the same time a high strategic and tactical capacity to develop growth and stabilized the operations at the same time, without letting innovation and creativity decline. The Matthew, Sonfield and Lussier Entrepreneurial Strategy Matrix to measure risk and innovation states that the higher the innovative goal pursued, the greater the risk that must be managed. As is the case with AI-first start-ups. This requires the difficult approaches to reduce risk through strict control of investments and operating costs, while maintaining the speed of innovation, and opting for joint-venture alliances to support growth (Kuratko, 2017). In the perspective of technology and innovation management, to achieve success in this transitional process requires internal motivation for enhancing innovative, creative performance, with at least two conditions should be met: a) clear goals, objectives with autonomy to act guided with supportive feedback (Katz, 2008). b) a team of technology professionals who have 
complementary motivational anchors in their careers; managerial, technical-functional, security-stability to entrepreneurial creativity, among the eight defined by Schein (1996).

In order to verify what has been said so far, we have developed this case by observing, analysing and describing the Japanese start-up Cogent Labs is an AI-based technological company that facilitates research and development and research protocols in solving problems using AI protocols. The methodology used has been to interview one of its co-founders and executive director, its AI architecture director, collaborate with them in delivering an academic conference, and follow the evolution of the company for a year and a half. With the purpose of demonstrating how a start-up based on the development of high technology can consolidate and quickly generate products based on $\mathrm{AI}$, in an environment unfavourable to entrepreneurship.

\section{ENTREPRENEURSHIP ECOSYSTEMS IN JAPAN}

Entrepreneurship is the combination of willingness and a passion to achieve goals and expectations. An empirical study in Japan reported that the number of growing start-up systems has decreased significantly as the population has grown in Japan. The factors influencing start-up ecosystems includes age consideration, education, family status, occupation, employment types, job tenure and industry types. Furthermore, based on empirical data, the age effect coefficient and willingness to undertake new adventures are significant determinants of the success of start-ups in Japan. Moreover, entrepreneurship offers the perfect terrain for continuous innovations, economic sustainability and increased employment potential deficit (Karlin, 2013).

Although in the 1980s the emergence of the Japanese economy was boosted by a large number of entrepreneurs, especially in the electronics sectors, machinery and automobiles with significant industrial competitiveness, the bursting of the financial bubble in 1990 left a scenario of stagnation with a period of global entrepreneurial relevance (Cusumano, 2016).

The current profiles of Japanese and North American companies differ substantially due to the dominance of large corporations with interests in almost all industries and financial sectors. Such companies are called keiretsus in Japan and are based on a socially-rooted culture based on the relationships of lifelong employment. Many of the start-ups are born of the so-called "intrapreneurship" as a spin-off from large companies.

Japanese high-tech start-ups originate from universities (Daly, 1998; Honjo, 2017), with some similarity to the British model. These university spin-offs are usually financed by emerging stock markets, with the funds coming from keiretsus and private equity income. Although the number of annual start-ups was significantly affected by the crisis, stabilizing at an average of 50 spin-offs between 2010 and 2013, the start-up ratio and number of employed entrepreneurs wishing to establish their own business have been on the decrease for decades. According to the Employment Status Survey study of 2012, one third of the founders of new companies are over 60 years old, and the ratio continues to grow (Okamuro et al., 2017). They are usually professionals with seasoned backgrounds in multinational companies who decide to invest their early retirement compensation in maintaining their professional activity with a greater degree of freedom.

On the other hand, universities focus on basic $\mathrm{R} \& \mathrm{D}$ strategies and preferably collaborate with corporations and accumulate patents and licenses, without developing business models (Ito et al., 2016), while governments decide to support large corporations in the promotion of innovation to recover global competitive capacity lost during 20 years of economic stagnation.

Any start-up that does not match these profiles will have to grow battling against this profoundly traditional social, business and political culture. A survey carried out in 2001 on 396 Japanese firms and 188 Silicon Valley firms concluded that Japanese entrepreneurs show social leadership: they are 
oriented towards social causes, in search of social recognition, and are mainly concerned with the effects of globalization, with great strategic focus on $\mathrm{R} \& \mathrm{D}$ without worrying much about financial risks. While Silicon Valley start-ups show an individual leadership profile, they are more motivated by factors such as personal achievement and accumulation of personal wealth, customer-focus, and the search for great opportunities that allow access to venture capital and offer rapid growth (Suzuki et al., 2001).

In Japan, according to empirical data the ratio of start-ups has been lower. The primary factor influencing the growth of start-up systems is the preparation involved, the willingness of the entrepreneur to create a start-up and properly established procedures that enable the acceleration of start-up ecosystems (Karlin, 2013). Another issue influencing start-up ecosystems in Japan is the higher ratio of senior entrepreneurs over the age of 60 (Karlin, 2013). These entrepreneurs are retired senior managers with an extensive background in a particular industry. Empirical studies suggested that a third of entrepreneurial founders are aged 60 years and above. Further analysis revealed a reduction in the ratio of younger founders. The willingness and preparedness to start up a business differ proportionately across the age range, as the pattern might change over the time. The primary determinant for the desire and development of a business start-up is a clear indication of the success of entrepreneurial ecosystems. The fundamental implication for increasing entrepreneurial ecosystems is to create awareness of their role in boosting innovations and improving economic sustainability. In contrast to the current Japanese tendency, Cogent Labs founders are in their thirties, and employees' average age is same as that of the founders.

Entrepreneurship focuses on improving the livelihood of the Japanese through the creation of an allinclusive society, thereby facilitating higher economic empowerment. The Japanese economy is more likely to be in the hands of larger corporations. Japanese ecosystems are expected to be boosted by open access to innovations and the ability of larger firms to adopt new ideas and develop innovative concerns that are more likely to address creative issues (Kushida, 2016, p. 4).

Japanese start-up ecosystems are more likely to grow due to increased market dynamics. Japanese venture capital is expected to grow dynamically, providing open access governance to greater approaches to industrialization techniques (Kushida, 2016, p. 4). The rise of independent venture capitalists increases returns on investment for start-up ecosystems. Entrepreneurship ultimately encourages the growth of business ventures and increases the rate of innovation and economic empowerment in Japan (Zhang, 2017).

A high start-up ecosystem rationale enhances the growth of commercial gross per capita formulation. The policy recommendation is likely to boost higher growth in the Japanese stock market. The New Economy Summit in Japan provides entrepreneurs life-changing opportunities to interact with highstake Silicon Valley entrepreneurs to achieve a formidable entrepreneurship culture for the Japanese nation. Furthermore, technological summits and conferences such as the Infinity Venture Summit attract substantially greater numbers of corporations to Kyoto on an annual basis to discuss auxiliary mechanisms of how best to improve their start-up ecosystems through a centralized hub of investors, entrepreneurs and high-start-up strategic partnership. Increasing support mechanisms is vital for the growth of business corporations through diplomatic partner valuation strategies (Ford, 2016). Furthermore, the best way of handling an increased start-up culture is to centralize its operation and create open governance methodologies to expand its economic empowerment (Ford, 2016).

Japan's economic empowerment should legitimize and provide access to incentives to start-up ecosystems solving real-world problems such as AI-driven optical character recognition. Furthermore, the governing authorities should create a comprehensive database that lists start-ups based on their revenues and should deduce policy recommendation through $\mathrm{R} \& \mathrm{D}$ with regard to how they can achieve optimum success. 
Japan start-ups should become start-up accelerators in order to scale their global presence. Moreover, there should be active efforts in strengthening university-government ties, thus boosting successful start-ups. Government policies are key growth pillars gauging the success of start-up entrepreneurial ecosystems. Through government policies, start-ups are given direct subsidies on goods and services, thus creating an advanced IT-enabled revolution. The Japanese government should create an open access market structure that addresses schematic concerns regarding how we can improve entrepreneurial issues.

\section{ECONOMIC EMERGENCE OF BUSINESS SMARTIZATION SOLUTIONS THROUGH AI}

The trend towards AI is influencing every sector of the world economy, not just in Japan. The OECD (2016) reported that the digital economy is disruptive "in particular [for] those with low or no formal education -lack the necessary skills and know-how-, and financial resources to take advantage of ICTs, and to introduce the changes needed for their productive use in businesses and across society" OECD (2016).

AI ecosystems have grown exponentially during the 21st century. Five of the six top world companies with the largest market capitalization are also the top five with an absolute increase in market capitalization: Apple Inc., Alphabet Inc. (Google), Amazon.Com Inc., Microsoft Corp. and Facebook Inc. are digital business model-based (PWC, 2017) and develop or/and use AI as a core operational competence in their business models. All these companies were ranked below position \#31, the best, in 2009 (see Figure 1).

We are entering the era of Big Data, with more than 40 billion web pages indexed on the Internet, 100 hours of video uploaded to YouTube every minute, trillions of real-time data generated by the Internet of Things and commercial networks in companies: Wal-Mart generates one million commercial transactions per hour and its databases contain more than 2.5 petabytes ( $2.5 \times 1015)$ of information, amounts that are growing exponentially. AI and Deep Learning feed on these huge amounts of data which are impossible to process with traditional methods because of their volume and complexity - to convert them into useful information for both prediction and decision-making processes. We can define Machine Learning as "a set of methods that can automatically detect patterns in data, and then use the uncovered patterns to predict future data or to perform other kind of decision-making under uncertainty (such as planning how to collect more data)" (Murphy, 2012).

The AI market is projected to almost triple from 2014 to 2020, which represents an increase in spending from $\$ 58$ billion to $\$ 153$ billion, according to research conducted by Bank of America Merrill Lynch (TWICE, 2017). According to a survey carried out by the research company Tractica (Armstrong \& Richter, 2016), the main AI applications and their estimated cumulative revenue 20162025 will be:

1. Static image recognition, classification and tagging

2. Algorithmic trading strategy performance improvement

3. Efficient, scalable processing of patient data

4. Predictive maintenance

5. Geospatial images object identification detection, classification, tracking

6. Text query images

7. Automated geophysical feature detection

8. Content distribution on social media

9. Object detection and classification-avoidance, navigation

10. Prevention against cybersecurity fraud
$\$ 8,097.9 \mathrm{~m}$

$\$ 7,540,5 \mathrm{~m}$

$\$ 7,366.4 \mathrm{~m}$

$\$ 4,680.3 \mathrm{~m}$

$\$ 4.201 .0 \mathrm{~m}$

$\$ 3,741.1 \mathrm{~m}$

$\$ 3,655.5 \mathrm{~m}$

$\$ 3,566.6 \mathrm{~m}$

$\$ 3,169.8 \mathrm{~m}$

$\$ 2,472.6 \mathrm{~m}$ 
From a large survey of machine learning, one study predicted that AI will outperform humans in many domains in the next 40 years, including language translation (by 2024), truck driving (by 2027), retail work (by 2031), writing a bestselling book (by 2049), and surgery (by 2053). Researchers believe there is a $50 \%$ chance of AI outperforming humans in all tasks in 45 years and of automating all human jobs in 120 years. Interestingly, Asian respondents expect these dates to be much sooner than North Americans (Grace et al., 2017).

AI is reshaping humankind's approach to science and technologies, industrialization, health, military and security influences. For instance, through the use of a proprietary algorithm, IBM Watson accurately predicts medical effects to a greater extent. AI also provides self-driving vehicles increased data processing capabilities, enabling them to undertake real-time decision-making.

Business process outsourcing (BPO) has enabled Cogent Labs and its business ecosystem to increase their decision-making capabilities, thereby increasing the potential for the revenue generated by the company and also improving the innovation potential for Japan. AI researcher predict that by 2025, AI will surpass the potential for improvement of human performance (Grace et al., 2017).

The transformation of business models, products, services, operations and processes driven by the realtime automation of decisions and control is fostered by five convergent drives: AI, IoT, Cyber-Physical Interfaces, Enabling Technologies — such as smart sensors, nanotechnology, Brain Computer Interfaces, 3D-Printing, etc.- and Emerging Sciences, including bio, neuro, and green sciences (see Figure 2).

\section{COGENT LAB'S TEGAKI AI}

Tegaki ("handwriting" in Japanese) is an AI solution that performs automatic character recognition. The challenges for the Tegaki AI character recognition framework were to increase the accuracy and reduce the processing time. In Japanese writing systems, Tegaki AI uses the minimum amount of time to process a larger batch of queued content from different handwriting styles (Cogent Labs Inc., 2017). Jun Inuma summarized Tadaki's value proposition as:

"For Tegaki is very simple - the service can perform the action that was previously done manually, this reduces the cost and speed. In the past a client may have to wait days while with Tegaki the results for a big batch can be done in a matter of minutes. For the financial service - it's a matter of providing insight that would have been difficult to get using more traditional methods. So, either we do what humans can do but cheaper/faster or we can do things which humans could not do, such as processing lots of time-series data and making predictions in near real-time." (Inuma, J. \& Malkin, 2017).

Tegaki AI uses proprietary algorithms to provide meaningful insights for the financial industries. In addition, Tegaki AI improves human coordination processes in real-time and generates time-series sequences necessary for making economic predictions and decisions-making processes. Using deep learning as the core technological enterprise, Cogent Labs develops proprietary algorithm processing information in real-time. Tegaki AI is essential for processing Japanese and Chinese Language Systems (Cogent Labs Inc., 2017).

The central importance of using Tegaki AI allows clients to massively reduce their BPO costs, aiding them to further improve their costs acquisition models. To fully achieve accurate Tegaki AI dynamics, Cogent Labs uses deep learning and neural network protocols to advance handwriting recognition protocols in real-time instances and the conversion of handwritten Japanese languages and writing systems into conceptual semantic text data using.

\section{THE NEW AI PARADIGM AND OHR}


By using AI-OHR API procedures, Cogent Labs improves business interactions with their advanced API communication algorithm (Tappert, Suen, \& Wakahara, n.d., p. 1123). OHR is necessary in scenarios where digitized content, both human and machine-encoded, should be readable and managed by IT systems. The challenge for OHR is to recognize digital content through a digital scanning paradigm. Optical recognition can be offline and online; online recognition identifies document elements during the same time the system's user types details into the computer when filling protocols. Using an AI-based approach, OHR can coherently increase the quality of synthesized elements through supervised deep-learning operating procedures. Automatic identification of scanned, digitized factors enhances the quality of the produced components through online and off-line recognition algorithms.

Through optical scanning, the digital content of an image is captured and translated into a centralized server for analysis. OCR has been used efficiently in meeting the end-user perspective of the human handwriting process by automating the process for systems users. OCR can cover aspects of centralized data entry process. A document scanning approach enables digitization of limited sets of printable elements such as typed textual data.

Through API, business processes can link with the established API calls to determine the verification patterns for Japanese writing pattern schematics. Furthermore, AI-OCR systems increase the verification patterns for OCR, enhancing structures where Cogent Labs' expert teams can adjust their B2B API to communicate in real-time with the business associated with OCR protocols. Moreover, advancing OCR enables recognition of constrained handwriting patterns that pose a problem for users of correlated handwritten characters. AI-OCR readers embedded in machine learning allow to create interconnectedness of information data semantics.

The accuracy of OCR systems depends on the quality of the input documents. Technical factors such as variation in shape attributes, deformation of textual elements and variation in spacing elements are a problem in developing accurate, concise AI-OCR systems, as they increase the errors generated thus affecting the viability of generic data elements. Cogent Labs intends to use AI systems to avoid humangenerated mistakes effectively.

AI-OCR provides auxiliary technology, enabling the development of a structured approach of converting various document types, including scanned elements, digitized documents and PDF files, into searchable data elements. AI embodies the ability to use broad machine-learning paradigms and an Artificial Neural Network (ANN) approach of scanning digitized images to extract synthetic textual data necessary for verification. OCR APIs can be used by business enterprises to examine digitized images, retrieve information and send textual data to a centralized server. OCR provides a better, faster, more coherent, scalable data capture algorithm, saving extensive time on resource constraints and time factors.

OCR enables the algorithmic recognition for deformation of handwriting systems preprocessing relevant data from the database templates. Traditional document imaging methods use models and algorithms in a two-dimensional environment to recognize objects and patterns. OCR methods today recognize a broader spectrum of colors and can dynamically distinguish between the background and the forefront in digitized documents. The proprietary algorithm de-skews, de-speckles and enables 3-D image correction to work with lower resolution scanned images. OCR software on the market today includes an imaging technology called matrix matching technological footprint. Matrix matching is a form of artificial intelligence which combines feature extraction and similarity measuring. Matrix matching technology brings new possibilities to OCR.

Furthermore, AI-driven OCR algorithmic patterns transform data inputs into distinct sets of features through feature extraction of the digital content. Feature detection manipulates raw data images through ANN. ANN algorithms transform digitized images through feature allocation space. 
Moreover, feature extraction enables extraction of scanned images to identify the properties and elements of character recognition patterns uniquely.

\section{CLOUD-BASED AI ONLINE HANDWRITING RECOGNITION ALGORITHM}

Using multiple keystrokes, Tegaki AI automatically and dynamically recognizes keystroke elements with real-time instances and transforms digital signatures into textual information in which Cogent Labs' Japan servers automatically convert critical strokes into analytic details. Cogent Labs develop API-based AI online handwriting software that can be embedded within business enterprise software and dynamically digitizes keystrokes in real-time instances.

Using pattern recognition and deep-machine-learning algorithms, machines can automatically detect Japanese writing systems. Online handwriting recognition software recognizes language symbols, thereby enabling the alphanumerical identification of the Japanese and Chinese Languages. Furthermore, AI online handwriting includes character segmentations and requires separation of textual elements captured from the user's computer systems (SoftWorks AI, 2017).

Discrete characters may require segmentations, which involves interaction between character segmentations and handwriting recognition. Pre-processing of online handwriting by the recognition algorithm enables the processing of handwriting data and importantly the recognition of shapes and patterns. Through character segmentation, the handwriting recognition patterns allow textual information to be extracted from the online recognition machine (SoftWorks AI, 2017).

In general, AI-driven OCR automatically predicts keystrokes and extracts textual data from multiple keystrokes to improve the data recognition algorithm. Handwriting consists of numerous strokes, which form each character in a sequential order, thereby forming character recognition patterns. Japanese writing systems include Hiragana, Katakana, Kanji and English alphanumerical attributes (SoftWorks AI, 2017). Tegaki AI doesn't need to know the order of keystrokes to perform the offline recognition in order to make the prediction.

Static and dynamic variation occurs within the typed elements representing each character in real-time scenarios. Dynamic variation captures multiple keystrokes from machine systems in real-time situations. Stroke direction determines the errors multiplier and evaluates the textual data information. Upper and lower-case characters serve as the baseline for handwriting variations and enable character segmentation. Online data capture refers to the capturing of data as the person writes. Using multiple neural network engines, the AI recognition algorithm observes users' stylus strokes and recognizes users' character elements, words and phrases elements.

Cogent Labs tries to adjust their AI protocols to include proprietary extensions that automatically read elements typed using users' stylus elements and attempts to deduce the character attrition and construct hypotheses based on it. Users type on the machine and the machine translates the document, assembling speculative information based on this information. The critical technological footprint required to create an interactive AI-based structure includes deep-learning technologies, machinelearning protocols, and ANN capability. Through sensor neurons, the profound learning principle leads to the creation of artificial neurons essential for recognizing patterns within image elements and trains the constructed network to facilitate fixed-point recognition of elements.

Embedded machine-learning protocols attempt to create an underlying artificial principle technology that uses using neural nodes to recognize writing systems such as Japanese, Chinese, and English. After the user types into the tablet devices using a computer stylus, it translates the footprint directly to the image database structure (Yasuda, Takahashi \& Matsumoto, 2000).

Advancing digital footprints entails scanning documents, capturing them from scanners and tablets, sending the captured images to database servers, and converting them into meaningful information 
such as text, graphics elements, mathematical notations or musical notations, thereby enabling users to transform the captured aspects through sharing, editing capabilities or searching for relevant features (Yasuda, Takahashi \& Matsumoto, 2000).

Tegaki AI technological innovation should have advanced cross-platform ability and be available for either web-version, standardized platforms or run on an embedded platform. Importantly, integrating it for business consumer purposes is necessary to create a proprietary structure through natural language processing (FKI: Research Group on Computer Vision and Artificial Intelligence INF, University of Bern, 2016). Using AI protocols, Tegaki AI solves the problem of manual entry of data entry. Using advanced web components and dominant API protocols, Tegaki AI can be integrated within BPO to meet the needs of organizations. Tegaki AI seamlessly recognizes handwriting elements within enterprise business structures and industries such as insurance, healthcare and banking (Metz, 2015).

\section{BUSINESS SMARTIZATION AND HANDWRITING RECOGNITION}

AI plays a significant role in innovation and enhances how businesses addresses the need to solve problems related to OCR dynamics and the automation of business processes. AI and Internet of Things (IoT) facilitate the incremental automation of business processes and non-strategic business decisions. IoT allows devices to connect and communicate across the globe in real-time. I refer to this AI- and IoT-driven business transformation of business processes and business decision automation as "Business Smartization". Cogent Labs invests in powerful technologies to connect more people to businesses and provides automated solutions in the AI sector. Business Smartization equips the company with strategies on how to create a sustainable society through adopting technological architecture (Keysers, Deselaers, Rowley, Wang, \& Carbune, 2017).

Business Smartization provides an increased flow of innovations to BPO. Business smartization processes increases the strategies Cogent Labs uses to influence the outcome of its innovation implications. Business Smartization can be illustrated in the following technical scope:

1. Technological approach. What strategy does Cogent Labs plan to implement in the advancement of Optical Character Recognition Techniques in improving AI handwriting concepts for business process automation?

2. Services and product design of AI-based algorithms. Can Cogent Labs improve the algorithmic procedure based on consumption patterns and solve human-oriented problems for automated business decision processes? The success of advancing Optical Character Recognition is directly dependent on the likeability of a product, consumption patterns and how OCR handwriting recognition devices are being designed in order to achieve handwriting behavioural recognition.

3. Business strategy. Entrepreneurship entails growing start-up ecosystems and influences the success of the algorithmic patterns. Cogent Labs uses the notion of algorithmic procedures to increase the financial growth of BPO protocols. Innovation is the key strategy in achieving and implementing newer ideas and enables Cogent Labs' R\&D team to enhance AI protocols in advancing the notion of OCR protocols in handwriting recognition algorithmic patterns.

Advancing handwriting technology is a critical competitive value on Cogent Labs' business smartization value proposition within entrepreneurship ecosystems. Recognizing document patterns is extremely easy for human beings but extracting them through deep-machine learning is complex. Offline and online handwriting provides unique challenges to in-depth learning protocols, combining each segment into a series of a defined length to create patterns using AI sequence BPO protocols. Languages such as Japan required advanced OCR algorithms to extract elements within sequences in real-time. Cogent Labs offers auxiliary research patterns on how we can advance our technological footprints, promoting OCR handwriting implementation algorithms using deep learning and AI architecture to increase automatic extraction of segmented elements, thereby improving our ability to view documents (Keysers, Deselaers, Rowley, Wang, \& Carbune, 2017). 


\section{DESCRIPTIVE ANALYSIS OF COGENT LABS}

\subsection{Business Smartization at Cogent Labs: Automating the OCR process using AI}

Under the assumption that business smartization is a process of automation of a process AI-driven. Cogent Labs plans to automate the process of OCR of the Japanese language to increase accuracy by offering end-users software-as-a-service (SaaS) capability.

Cogent Labs is offering BPO capability by providing cloud software solutions to dynamic clientele markets. Furthermore, Cogent Labs intends to develop OCR capability with the potential of using AIcentric solutions to achieve credit management potential in order to prove the authenticity of application entered in the OCR system. Automating OCR capability in Japan is an advanced problem that requires start-up influence to enable the business enterprise to generate solutions for the problem, as the leading role of business start-ups is to create solutions for a given problem.

The automation of OCR is a particular extended problem in Japan and requires the application of AI to increase decision-making potential in proving the authenticity of credit card applications. Using enhanced business smartization, business enterprises create a correct trajectory for which entrepreneurial ecosystems can produce proof of concepts, increase accuracy and provides rapid monetization. AI-driven BPO enables to transform business enterprises by advancing the decisionmaking potential of the organization.

\subsection{Drivers for business smartization}

The exponential transformation of Cogent Labs' business models, services, operations and processes increases the real-time processing of decisions. AI ecosystems are a critical technological pillar for shaping the future and changing how OCR recognizes digital signatures within credit card processing using conceptual, proprietary algorithms. Using proprietary handwriting recognition algorithms with a precision rate of $99.2 \%$ (see Figure 3), Tegaki AI aims to eliminate complex, inaccurate manual data entry from application forms using Japanese writing systems. API protocols retrieve JSON data types via APIs to communicate via distributed database servers and interact with the business enterprise OCR application to monitor for credit application digital patterns (Tappert, Suen, \& Wakahara, n.d., p. 1123).

\subsection{Benefits of advancing AI-OHR}

AI increases the growth potential of OHR in Japanese writing patterns. Using AI-powered OCR influences the sales of start-ups by enabling the generation of revenue-generating models. AI capability to solve human-oriented problems increases the sales of OCR components exponentially. Furthermore, by advancing OCR towards AI helps:

1. It boosts sales generated by promoting AI.

2. It efficiently boosts operations. AI boosts operational efficiency.

3. Advancing artificially induced handwriting recognition increases customer satisfaction.

4. Entrepreneurs can use AI to boost insights into consumers and enable better market analysis.

5. Start-ups can use AI to increase productivity potential, decrease productivity constraints by lowering operational costs.

\subsection{Cogent Labs' business smartization model: business process outsourcing}

Business smartization enhances automated AI Optical Recognition Protocols (ORPs) for OHR, thereby improving insight into customers and thus enabling them to make better decisions: 
1. To promote business growth and innovation strategy.

2. To enhance customer experience and value proposition.

3. To increase through OHR business adaptability, alignment and agility.

4. To create data strategy, thereby influencing growth potential for knowledge intelligence.

BPO involves contracting specific subcomponents of computer systems with the aim of improving the efficiency and accuracy of processes in the organization. Through its BPO framework, Cogent Labs intends to develop AI capability to reduce operation costs, improve efficiency and upgrade the functionality of the OCR components. AI is revolutionizing how business interactions are handled through centralized API access.

Tegaki AI API provides an auxiliary mechanism where the end users access JSON AI tokens in realtime, facilitating increased, automatic communication between the distributed parties. Through the structured OCR toolkit, end-users can look at a real-time interaction between clients. Most businesses will benefit immensely from creating sustainability through AI-powered systems.

To improve the accuracy of the OHR systems, data structures are crowdsourced from different business enterprises to simultaneously perform data validation and verification (Tappert, Suen, \& Wakahara, n.d., p. 1124). OCR-OHR transaction detection, crowdsourced data validation, and algorithmic reconciliation increases the accuracy and consistency of users' writing patterns, enabling them to construct meaningful data insight based on database servers' information retrieved through the AWS (Amazon Web Services) toolkit (Tappert, Suen, \& Wakahara, n.d., p. 1124).

The pros and cons of using BPO for Cogent Labs for advanced OHR are:

1. Using BPO saves considerable time required to develop proprietary OCR algorithmic patterns.

2. Saves time required that is distributed uniformly in the management of core competencies of the applications.

3. Increased insights into consumers are necessary to facilitate accurate, efficient algorithmic procedures.

4. Enables real-time data analytics patterns.

5. Enables the use of third-party API functionality essential for generating solutions for a given problem.

6. Contacting through BPO is an important concept to enable stimulated business acceleration, since it reduces costs and exponentially increases the quality of services (QoS) for business growth.

\section{COMPONENTS OF AI-OCR SYSTEMS}

\subsection{Optical scanning}

AI-OCR improves the functionality of handwriting recognition processes through which digital scanners scans an original document. OHR fundamentally converts multilevel data images into scanned digital conversion images (Wright, 2015).

Advanced AI-OHR segments the constituent of pixels, including company logos, business imprints, stamping purposes, and recognizes stamps and high-density company images. AI-based human recognition structures increase the resolutions of pictures through OHR patterns (Wright, 2015).

\subsection{Feature extraction}


The objective of creating AI-OCR is to enable feature extraction to capture the essential characters of digitized images. Cogent Labs' OCR API rasters the pixel characteristics of models by increasing the threshold of images elements.

\subsection{Optical Handwriting Recognition}

OHR describes the recognition by an algorithm of users' keystrokes in real-time. As the user types on the machine, the algorithm dynamically deduces the keystrokes and processes the request in real-time. The recognition technique directly depends on the speed of the computer systems, the lag time of the computer systems and the technological structure of the AI handwriting recognition techniques (Wright, 2015).

In OHR, the transducer elements capture the keystrokes, determines the patterns of the writing through advanced sampling rate of 200 points per inch through scanners and digitizers such as tablets. Advances through AI increases the recognition ability of data captured techniques (Pham, Bluche, Kermorvant, \& Louradour, 2014, p. 5).

\subsection{Technical feasibility}

The central question to answer while developing technical feasibility is the aim of the project in meeting end-user requirements. Is the required technology essential for solving errors in human handwriting patterns?

During the creation of an advanced system, information experts thoroughly analyze the merits of developing versioned systems and how the methods can meet increased user expectations. What are the significant barriers to information? OCR-OHR requires advanced human expertise and therefore a fundamental software metrics on the artificial intelligence resolution paradigm.

\subsection{Economic feasibility}

Economic feasibility generates the costs implication of developing an AI-OCR conceptualized model. Furthermore, financial viability weighs on the merits of advancing new information systems and how it can enable users to achieve improved human interaction patterns. Economic feasibility necessitates planning procedures and provides top management with economic justifications for advancing their new technological enterprise. The potential future market is huge for Cogent Labs' Tegaki AI-OCR solution, with a predicted cumulative revenue of $\$ 3,741.1 \mathrm{~m}$ between 2015 and 2025 (Armstrong \& Richter, 2016).

Moreover, the benefits of increased automation from the companies' perspectives includes expanding human interaction and improving their mechanisms for making timely, quality decisions, thereby improving their accuracy of standard operation. Increased automation also significantly contributes to correct entrepreneurship policies for Japan. Economic feasibility tests estimate the success rationale of entrepreneurship models and start-up bubbles across Japan to improve the revenue-generating model in Japan.

\section{COGENT LABS ORGANIZATIONAL CULTURE: SOLVING THE MISMATCH OF PROFESSIONAL CULTURAL BEHAVIOURS}

According to Dr Malkin (2018), "AI scientists view their software as an exoskeleton. ML engineers view their software as a robot". The key success factor is to eliminate the gap in perspectives between the characteristic cultures of scientists and engineers. Cultures that, by their very nature, differ considerably, since scientists tend towards abstraction, whilst engineers only accept practical results, with the two groups demonstrating a notable inability to collaborate. Scientists prioritise maximizing 
knowledge through isolated conceptual models. Conceptual models that engineers find extremely difficult to quickly convert into real products that need to consider many other factors in addition to their feasibility in being produced and providing value to clients. Hence, many companies that implement AI-ML systems have serious difficulties in managing to monetize their AI solutions.

The AI Scientist's Approach:

- Seek accuracy and/or performance match domain.

- Create new algorithms and code samples to validate them.

- May be embedded in product teams.

The ML Engineer's Approach:

- Ensure model metrics match product metrics.

- Manage code and data inventories.

- Track model performances during product lifetime.

\subsection{Cogent Labs Product Development: Building ML Products Faster}

The solution of Cogent Labs to solve this clash between professional cultures, entails two fundamental aspects: build collaborative cross-functional product teams and recreate products for experimentation, making everyone understands what is being done and what results can be expected, with continuous supportive feedback.

\subsection{Collaborative Approach by Cross-Functional Product Teams}

The problem lies in the fact that even with the best AI scientists available, they are faced with serious difficulties in communicating outside of their strictly regulated scientific environment and in defining metrics that align with the product's needs. They tend to build parallel prototypes, recreating production models to iterate and systematically value accuracy improvement over maintainability/scalability concerns.

Because of this, a culture of collaboration needs to be created between scientists and engineers as well the sales team and clients, involving them in the product's development cycle. This involves taking on scientists who understand software engineering, equipping them with the tools to iterate ideas -always around the product- with the collaboration of engineers, thereby rewarding maintainability, stability, complexity and reduction.

The function of ML engineers is to professionalize the model design with the idea of developing a viable product from the beginning. They need to understand scientific models, their limitations and to be able to improve them, and to work with researchers in order to understand new concepts and research ideas.

Understanding, both scientists and engineers, that the model itself is a small part of an AI-ML system. This collaborative approach involves engineers in the research process, and also involve marketing and sales people, together with key clients (co-creating) in the development process.

\subsection{Recreate Production for Experimentation}

Dr Malkin summarises emphasizes the importance of creating an environment that facilitates experimentation and the construction of prototype/models to improve communication and collaboration between teams, setting common expectations and goals: "[The] traditional split of 
infrastructure between production, where the infra is well-defined, scalable, and ML teams, where the infra is ad hoc, customized, is slowing innovation in AI products".

- Build you production system to be clonable for experimentation.

- Set up integration testing for model updates.

- Build pipelines so that training is part of production.

In this way (Figure 4) Cogent Labs has designed a cooperative organizational culture that has allowed it to create a general AI-ML system for the automation of business processes -Business Smartizationwith solutions such as the processing of manually written, spoken or even unstructured information, and Big Data with its Time-Series Forecasting solution, which also incorporates information sources and external networks.

This AI-ML system is growing to be a general AI system in terms of scalability, providing increasing productivity through the implementation of extended Business Smartization in AI-driven companies. Something similar occurred in the era before Business Digitalization in terms of the need to transform data into information, except that now the capacity exists to convert this massive, unconnected, unstructured information, coming from various sources and knowledge-diffuse, into automatic decisions AI-driven with exponential results.

\subsection{Evolution of AI product developments}

Thanks to the collaborative and cross-functional management of projects, the research and development lines have been expanded, incorporating two new ones: Natural Language Processing and Times-Series. Having in June 2018, three lines of research in different stages of commercialization, and new product Kaidoku based on NLP (Cogent Labs, 2018). What represents a high capacity of development of projects and quantity that reaches its phase of commercial viability.

1. Image Recognition: Tegaki:

1. Handwriting Recognition.

2. Hierarchical Document Understanding.

2. Natural Language Processing: Kaidoku:

1. Sequence-to-Sequence Learning.

2. Latent Variable Models.

3. Information Extraction.

3. Times-Series:

1. Financial Time-Series Farecasting.

2. Brain-Computer Interfaces.

\section{CONCLUSION}

The process of advancing OHR patterns is fundamental in ensuring the automatic prediction of users' keystrokes, analysing multiple keystrokes instantaneously and evaluating the projections, making a conclusive argument based on the predictions. Using the advanced capabilities of AI, a business enterprise can construct document recognition algorithms that predict the outcome of the attributes and deduces whether the digitized content meets required scenarios. Furthermore, advances in online and offline recognition patterns automatically makes the discrete communication elements. Spacing distinct characters allow character segmentations are deducing better hypothesis for user perspective.

Cogent Labs plans to create AI-enabled API procedure calls for businesses by facilitating full recognition of characters to make communication real-time and enable the creation of prerequisite 


\section{sciendo}

International Journal of Entrepreneurial Knowledge

Issue 2/2018, Volume 6

character recognition patterns. Through entrepreneurship, Cogent Labs intends to upgrade its Tegaki AI and discretely shape character segmentation, allowing pre-processing of character elements that require distinguishing between character and numerical elements. Cogent Labs strives to strengthen their provision of AI systems for handwriting recognition algorithms.

While developing its first AI product, the start-up has built a structure capable of applying the knowledge acquired and the experience accumulated in AI-ML through a collaborative, crossfunctional organization, which creates motivation for scientists, engineers and professionals alike. The main key Success factor is to eliminate the gap in perspectives between the characteristic cultures and motivations of AI scientists and ML engineers, empowering team work. Cogent Labs achieves that by two approaches: a) collaborative approach by cross-functional product teams, and b) Recreate production for experimentation, where everyone understands what is being done and what results can be expected, with continuous supportive feedback.

Cogent Labs has demonstrated ability to overcome the transitional stage of the first entrepreneurship to stability and sustainability through the management, while at the same time keeping innovation by adding NLP and Times-Series, and creativity by rapidly developing products -Kaidoku and TimesSeries-. Fulfilling the premises established in the initial Scope and Objectives of this article.

Figure 1 Global Top 100 Companies by market capitalization, 31 March 2017 update

\section{Top 100 global companies 1-20}

\begin{tabular}{|c|c|c|c|c|c|c|c|}
\hline \multirow[t]{2}{*}{ Company name } & \multirow[t]{2}{*}{ Nationality } & \multirow[t]{2}{*}{ Industry } & \multirow{2}{*}{$\begin{array}{c}\text { Rank } \\
+/-\end{array}$} & \multicolumn{2}{|c|}{ 31 March 2017} & \multicolumn{2}{|c|}{ 31 March 2009} \\
\hline & & & & Rank & $\begin{array}{c}\text { Market Cap } \\
\text { (\$bn) }\end{array}$ & Rank & $\begin{array}{c}\text { Market Cap } \\
\text { (\$bn) }\end{array}$ \\
\hline Apple Inc & United States & Technology & 32 & 1 & 754 & 33 & 94 \\
\hline Alphabet Inc-Cl A & United States & Technology & 20 & 2 & 579 & 22 & 110 \\
\hline Microsoft Corp & United States & Technology & 3 & 3 & 509 & 6 & 163 \\
\hline Amazon.Com Inc & United States & Consumer Services & - & 4 & 423 & NA & 31 \\
\hline Berkshire Hathaway Inc-Cl A & United States & Financials & 7 & 5 & 411 & 12 & 134 \\
\hline Facebook Inc-A & United States & Technology & - & 6 & 411 & - & - \\
\hline Exxon Mobil Corp & United States & Oil \& Gas & -6 & 7 & 340 & 1 & 337 \\
\hline Johnson \& Johnson & United States & Health Care & o & 8 & 338 & 8 & 145 \\
\hline Jpmorgan Chase \& Co & United States & Financials & 19 & 9 & 314 & 28 & 100 \\
\hline Wells Fargo \& Co & United States & Financials & 45 & 10 & 279 & 55 & 60 \\
\hline Tencent Holdings Ltd & China & Technology & - & 11 & 272 & - & 13 \\
\hline Alibaba Group Holding-Sp Adr & China & Consumer Services & - & 12 & 269 & - & - \\
\hline General Electric Co & United States & Industrials & 11 & 13 & 260 & 24 & 107 \\
\hline Samsung Electronics Co Ltd & South Korea & Consumer Goods & 39 & 14 & 259 & 53 & 61 \\
\hline At\&T Inc & United States & Telecommunications & -8 & 15 & 256 & 7 & 149 \\
\hline Ind \& Comm Bk Of China-A & China & Financials & -12 & 16 & 246 & 4 & 188 \\
\hline Nestle & Switzerland & Consumer Goods & -2 & 17 & 239 & 15 & 129 \\
\hline Bank Of America Corp & United States & Financials & 69 & 18 & 236 & 87 & 44 \\
\hline Procter \& Gamble & United States & Consumer Goods & -9 & 19 & 230 & 10 & 138 \\
\hline China Mobile Ltd & Hong Kong & Telecommunications & -15 & 20 & 224 & 5 & 175 \\
\hline
\end{tabular}




\section{The risers - the 20 Global Top 100 companies with the largest absolute increase in market cap}

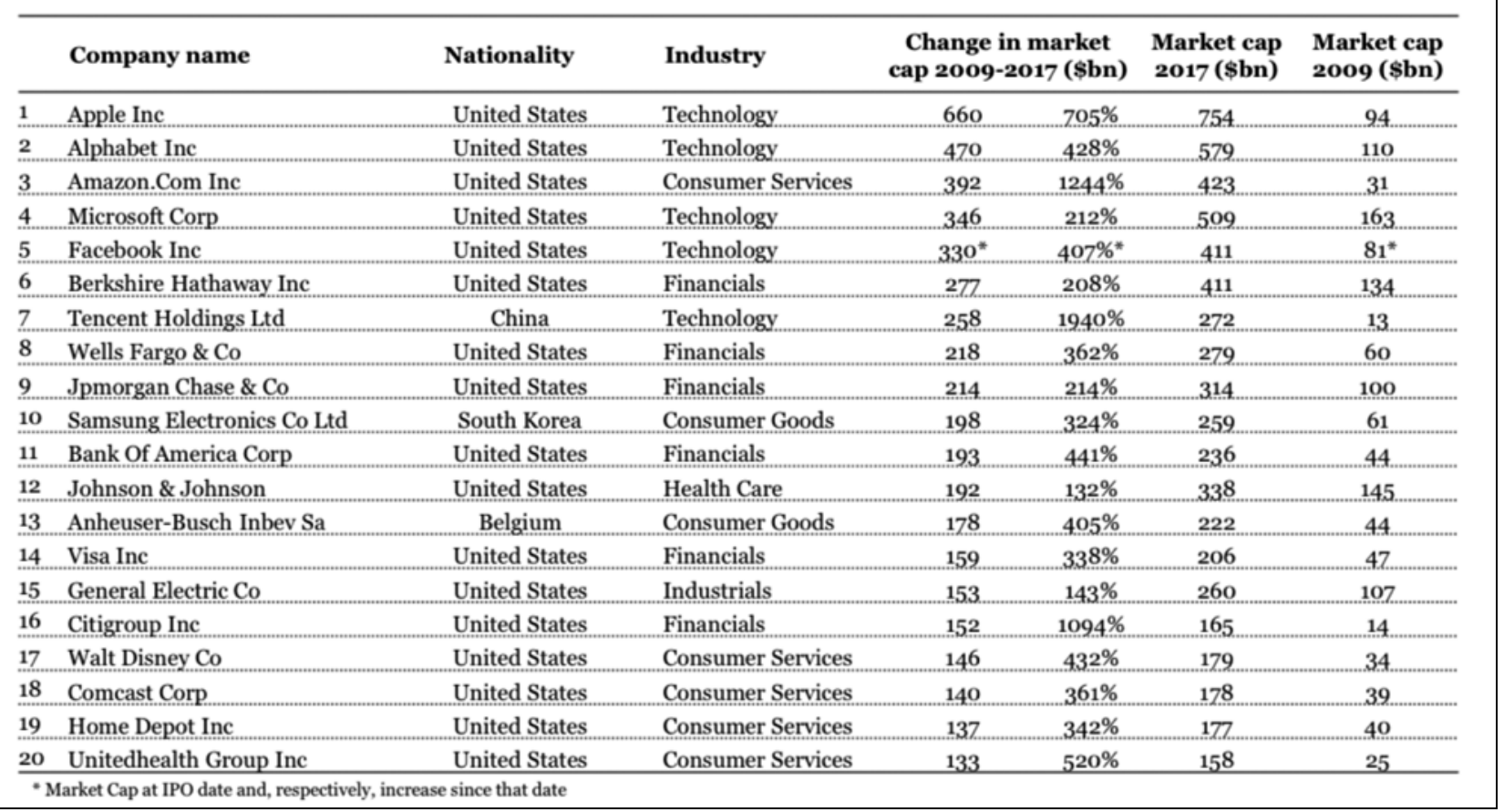

(Source: PWC, 2017) 
Figure 2 Five drivers of Business Smartization: Exponential transformation of business models, products, services, operations and processes driven by real-time automation of decisions and control

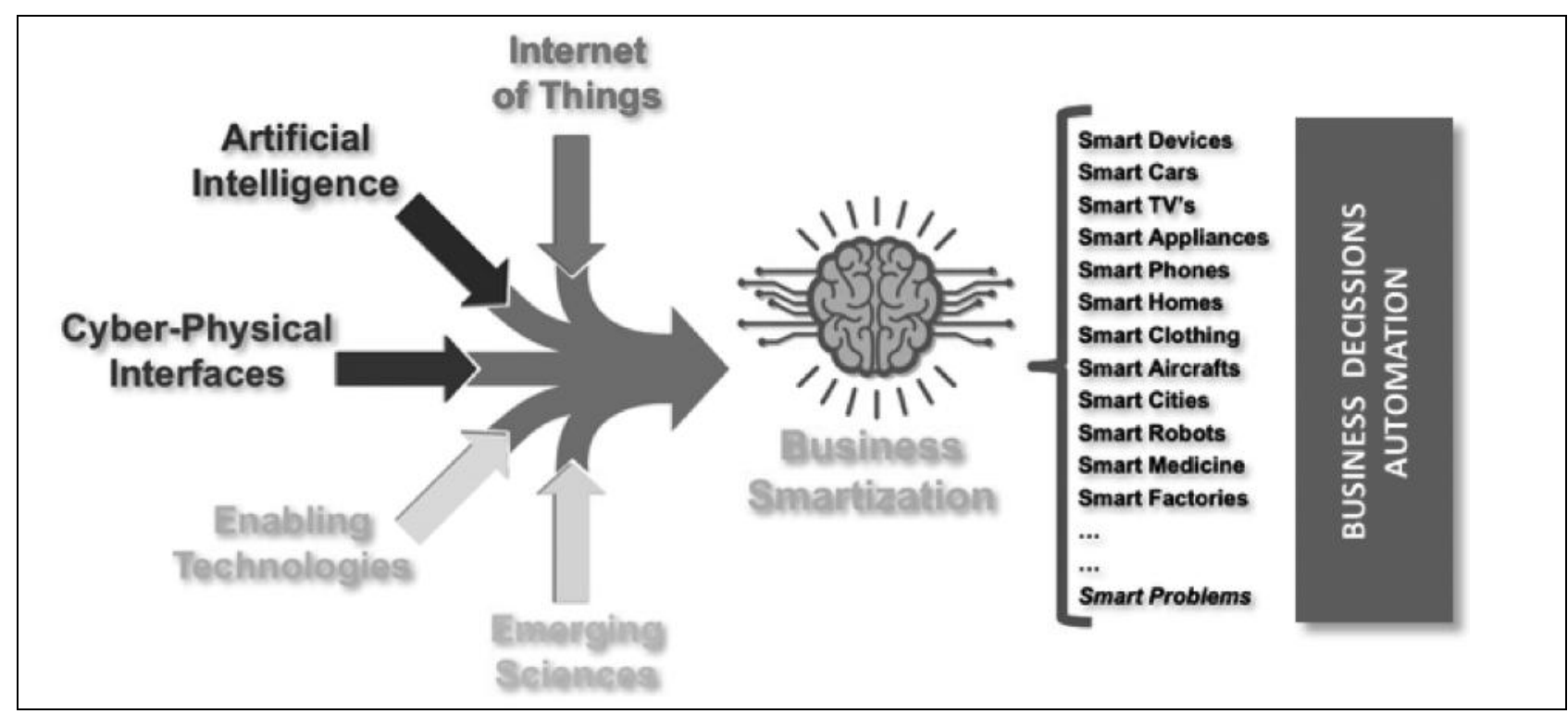

(Source: Author)

Figure 3 Example of handwriting to text recognition from five different handwritten sources processed by Tegaki AI

青铜の魔人

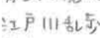

歯事喑

冬の夜、月のさえた晩、银座通しに近い格のたもとの交翻に、ひとりの 警官が夜の見はりにっいているした。一時をとっくにすを゙た直夜中です。 ひるまは要事やバスや自䡃事が、縦横にはせちがう 大通りも、まるていなかの原っぱのようにされしいのです。 月の光に、四本の電事のレルボキラキラ光って、るばかり、 郵くものは、何もあり娄七ん。束京中の人が死にたえ7 しまたようなさびしさたす。

管官は、交番の东い電灯の下に、じっと立って、注意はぶがくあたりを見

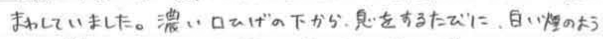
なヒのが站のばています。寒さに息がュおるのです、

「オヤ、ヘんなやっだな゙。よっぱらいがなっ」

警官が思わガムとりごとをつぶせきました。

キラキラ光った電車のしールのまいまん中を、ひとリの累が茮いてくる

のです。青い色の背広に、青い色のソフトをがジた大男です。つの寒い のに外套も着乙いません。

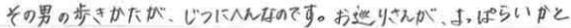

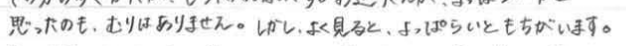

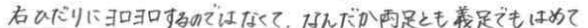
いるような步、かたなのてす。人間の足で频くのではなく、機械くできた 足で步いていなうな脣じです。

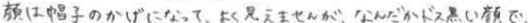

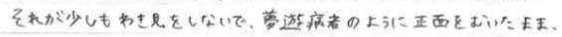

ガックリガックリ歩いているのです。
青銅の魔人江戸川乱歩歯車の音冬の夜、月のさえた晩、銀座通りに近い 橋のたもとの交番に、ひとりの警官が夜の見はりについていました。一 時をとつつくにすぎた真夜中です。ひるまは一電車やバスや自動車が、 縦横にはせちがう大通りも、まるでいなかの原っぱのようにさびしいの です。月の光に、四本の電車のレ一二ルがキラキラ光つているばかり、 動くものは、何もありません。東京中の人が死にたえてしまったような さびしさです。警官は、交番の赤い電灯の下に、じっと立って、注意ぶ かくあたりを見まわしていました。濃い口ひげの下から、息をするたび に、白い煙のようなものが立ちのぼつています。寒さに息がこおるので す。「オヤ、へんなやつだなあ。よつぱらいかな。」警官が思わずひと りごとをつぶやきました。キラキラ光つた電車のレ一二ルのまんまん中 を、ひとりの男が歩いてくるのです。青い色の背広に、青い色のソフト をかぶった大男です。この寒いのに外套も着ていません。その男の歩き かたが、じつにへんなのです。お巡りさんが、よつぱらいかと思ったの も、むりはありません。しかし、よく見ると、よっぱらいともちがいま す。右ひだりにヨ口ヨ口するのではなくて、なんだか両足とも義足でも はめているような歩きかたなのです。人間の足で歩くのではなくュ機械 でできた足で歩いているような感心゙です。顔は帽子のかげになって、よ く見えませんが、なんだかドス黒い顔で、それが少しもわき見をしない で、夢遊病者のように正面をむいたまま、ガックリガックリ歩いている のです。

(Source: Cogent Labs Inc., 2017) 
Figure 4 Cogent Labs cross-cultural collaborative approach for faster development of AI-ML products

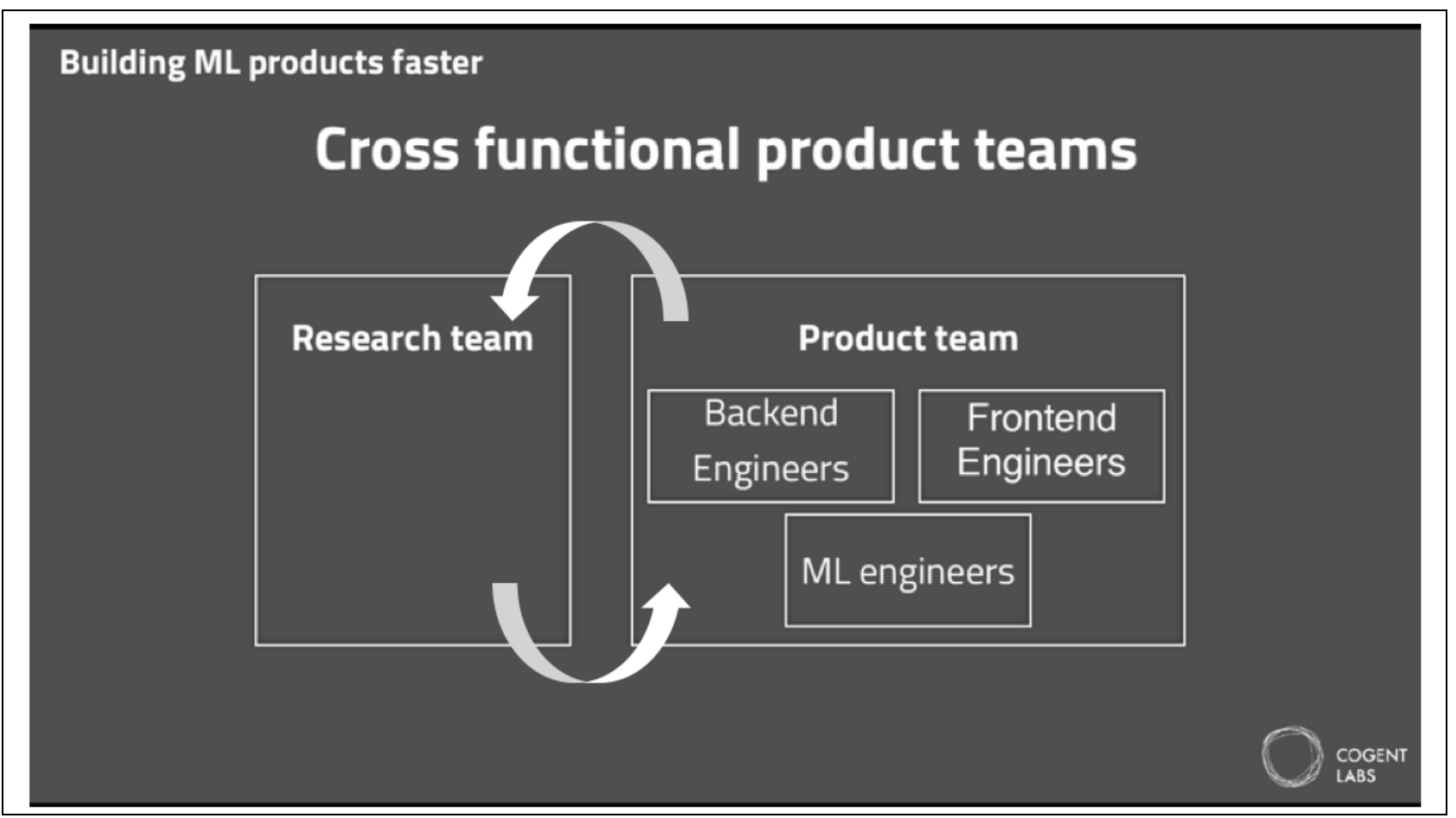

(Source: Malkin, 2018)

\section{REFERENCES}

Amin, A. (n.d.). Off line Arabic character recognition: a survey. Proceedings of the Fourth International Conference on Document Analysis and Recognition. doi:10.1109/icdar.1997.620572

Armstrong, M. \& Richter, F. (2016, November 18). Infographic: The Future Of A.I. Retrieved December 27, 2017, from https://www.statista.com/chart/6810/the-future-of-ai/

Calo, R. (2015). Robotics and the lessons of cyberlaw. "California Law Review", 103:513, 2015.

Cogent Labs Inc. (2018). Cogent Labs: Shaping the future with Artificial Intelligence. Retrieved June 18, 2018, from https://www.cogent.co.jp/en/

Cogent Labs Inc. (2017). Cogent Labs: Shaping the future with Artificial Intelligence. Retrieved December 14, 2017, from https://www.cogent.co.jp/en/

Cogent Labs Inc. (2017). Tegaki AI-OCER. Retrieved December 14, 2017, from https://www.tegaki.ai/

Cusumano, M. A. (2016). The puzzle of Japanese innovation and entrepreneurship. Communications of the ACM, 59(10), 18-20.

Daly, G. (1998). Entrepreneurship and business culture in Japan and the U.S. Japan and the World Economy, Volume 10(20), 487-494. Available at Science Direct: http://www.sciencedirect.com/science/article/pii/S0922142597000157?via\%3Dihub

FKI: Research Group on Computer Vision and Artificial Intelligence INF, University of Bern. (2016, February 6). IAM On-Line Handwriting Database - Computer Vision and Artificial Intelligence. Retrieved December 14, 2017, from http://www.fki.inf.unibe.ch/databases/iam-on-linehandwriting-database

Ford, P. (2016, May 17). Barriers to entrepreneurship in Japan. Retrieved from https://home.kpmg.com/xx/en/home/insights/2016/05/barriers-to-entrepreneurship-injapan.html 
Garain, U., Chaudhuri, B., \& Pal, T. (n.d.). Online handwritten Indian script recognition: a human motor function-based framework. Object recognition supported by user interaction for service robots. doi:10.1109/icpr.2002.1047820

Grace, K., Salvatier, J., Dafoe, A., Zhang, B., \& Evans, O. (2017). When Will AI Exceed Human Performance? Evidence from AI Experts. Artificial Intelligence (cs.AI); Computers and Society (cs.CY) arXiv preprint arXiv:1705.08807. Corney University Library. Available at: https://arxiv.org/pdf/1705.08807.pdf

Handwriting Recognition By Machine Learning. (2016, September 23). Retrieved December 14, 2017, from http://pclub.in/project/2016/09/23/Ml_HR.html

Honjo, Y. (2017). High-Tech Start-Ups in Japan: The Case of the Biotechnology Industry. Competition, Innovation, and Growth in Japan (pp. 149-176). Springer Singapore.

How to rev up Japanese start-ups. (2016, November 5). Retrieved December 14, 2017, from https://www.economist.com/news/business/21709578-japan-needs-do-more-encourage-newbusinesses-how-rev-up-japanese-startups

Inuma, J. \& Malkin, D. (July 29, 2017). Personal Interviews with Jun Inuma, founder and CEO, and David Malkin, Research AI Architect at Cogent Labs Japan.

Ito, T., Kaneta, T., \& Sundstrom, S. (2016). Does university entrepreneurship work in Japan?: a comparison of industry-university research funding and technology transfer activities between the UK and Japan. Journal of Innovation and Entrepreneurship, 5(1), 8.

Jäger, S., Liu, C. L., \& Nakagawa, M. (2003). The state of the art in Japanese online handwriting recognition compared to techniques in western handwriting recognition. International Journal on Document Analysis and Recognition, 6(2), 75-88.

Katz, R. (2008). Managing the innovative performance of technical professionals. At Shane, S. (Ed.) Hanbook of Technology and innovation Management. Sussex: John Wiley \& Sons Ltd.

Karlin, A. R. (2013, March 22). Entrepreneurship in Japan. Retrieved December 14, 2017, from https://global.wharton.upenn.edu/entrepreneurship-in-japan/

Kessentini, Y., Burger, T., \& Paquet, T. (2010). Evidential Combination of Multiple HMM Classifiers for Multi-script Handwriting Recognition. Computational Intelligence for Knowledge-Based Systems Design, 445-454. doi:10.1007/978-3-642-14049-5_46

Keysers, D., Deselaers, T., Rowley, H. A., Wang, L., \& Carbune, V. (2017). Multi-Language Online Handwriting Recognition. IEEE Transactions on Pattern Analysis and Machine Intelligence, 39(6), 1180-1194. doi:10.1109/tpami.2016.2572693

Kuratko, D. F. (2017). Entrepreneurship: Theory, Process, Practice. Boston: Cengage Learning.

Kushida, K. E. (2016). The Impact of Digital Technologies on Innovation Policy. SSRN Electronic Journal. doi:10.2139/ssrn.2856155

Kushida, K.E. (2017), Innovation and Entrepreneurship in Japan: Why Japan (Still) Matters for Global Competition. SVNJ Working Paper No. 2017-2. Available at SSRN: https: / / ssrn.com/abstract $=2956898$

Malkin, D. (April, 2018). AI-First Companies: Implementation and Impact. Keynote speech GLOBIS University School of Management Tokyo. Video retrieved July 14, 2018, from https://e.globis.jp/article/965

Metz, C. (2015, November 9). Google Just Open Sourced the Artificial Intelligence Engine at the Heart of Its Online Empire. Retrieved December 14, 2017, from https://www.wired.com/2015/11/google-open-sources-its-artificial-intelligence-engine/

Murphy, K.P. (2012). Machine Learning. A Probabilistic Perspective. Cambridge: Massachusetts Institute of Technology.

MyScript. (2017). MyScript Labs | MyScript. Retrieved December 14, 2017, from https://www.myscript.com/about/myscript-labs/

Nakai, M., Akira, N., Shimodaira, H., \& Sagayama, S. (2001). Substroke approach to HMM-based online Kanji handwriting recognition. Document Analysis and Recognition, 2001. Proceedings. Sixth International Conference on (pp. 491-495). IEEE.

Navigli, R. \& Ponzetto, S.P. (1999). Applications of Artificial Intelligence. Artificial Intelligence Special Issue, 114(1-2), 1-2. doi:10.1016/s0004-3702(99)00086-7 
NeuroScript. (2017). NeuroScript Computer Science handwriting analysis and handwriting recognition software. Retrieved December 14, 2017, from http://www.neuroscript.net/computerscience.php

OECD (2016). Stimulating digital innovation for growth and inclusiveness: The role of policies for the successful diffusion of ICT. Retrieved December 20, 2017, from http://www.oecd.org/officialdocuments/publicdisplaydocumentpdf/?cote=DSTI/ICCP(2015)1 8/FINAL\&docLanguage $=$ En

Okamuro, H., Ikeuchi, K., Matsuda, N., \& Tsuchiya, R. (2017). Who wishes to be an entrepreneur and who prepares for that?: Evidence from statistical micro data in Japan over 30 years.

Pham, V., Bluche, T., Kermorvant, C., \& Louradour, J. (2014). Dropout Improves Recurrent Neural Networks for Handwriting Recognition. 2014 14th International Conference on Frontiers in Handwriting Recognition. doi:10.1109/icfhr.2014.55

PWC (2017). Global to 100 companies by market capitalization. 31 March 2017 Update. Retrieved December 22, 2017, from https://www.pwc.com/gx/en/audit-services/assets/pdf/global-top100-companies-2017-final.pdf

Rusell, S. \& Norving, P. (2016). Artificial Intelligence. A Modern Approach. Essex: Pearson Education Limited.

Sasanuma, S., \& Fujimura, O. (1971). Selective impairment of phonetic and non-phonetic transcription of words in Japanese aphasic patients: kana vs. kanji in visual recognition and writing. Cortex, $7(1), 1-18$.

SELVAS AI Inc. (2017). Overlapped Handwriting recognition, handwriting input method editor online. Retrieved December 14, 2017, from https://www.selvasai.com/en/handwriting-recognitionsolution.php

SoftWorks AI. (2017). Handwriting Recognition Software - Softworks AI. Retrieved December 14, 2017, from https://softworksai.com/?libraries=handwriting-recognition-software

Stanford. (2017). Innovation and Entrepreneurship in Japan: Why Japan (Still) Matters for Global Competition. Retrieved December 14, 2017, from https://fsi.stanford.edu/sites/default/files/ssrn-id2956898.pdf

Suzuki, K. I., Kim, S. H., \& Bae, Z. T. (2002). Entrepreneurship in Japan and Silicon Valley: a comparative study. Technovation, 22(10), 595-606.

Tappert, C. C., Suen, C. Y., \& Wakahara, T. (1990). The state of the art in online handwriting recognition. IEEE Transactions on pattern analysis and machine intelligence, 12(8), 787-808.

Tappert, C., Suen, C., \& Wakahara, T. (n.d.). Online handwriting recognition-a survey. [1988 Proceedings] 9th International Conference on Pattern Recognition. doi:10.1109/icpr.1988.28459

TWICE. (2017, November 8) Artificial Intelligence Is Getting Smarter. Retrieved from https://www.twice.com/blog/how-ai-pervading-and-enhancing-consumer-electronics-65558

Wakahara, T., \& Odaka, K. (1997). On-line cursive Kanji character recognition using stroke-based affine transformation. IEEE Transactions on Pattern Analysis and Machine Intelligence, 19(12), $1381-1385$.

Wakahara, T., Murase, H., \& Odaka, K. (1992). On-line handwriting recognition. Proceedings of the IEEE, 80(7), 1181-1194.

Wright, M. (2015, July 24). This AI experiment can generate realistic handwriting. Retrieved from https://thenextweb.com/apps/2015/07/24/ballad-of-roy-batty/

Yasuda, H., Takahashi, K. \& Matsumoto, T. (2000). A discrete HMN for online handwriting recognition. International Journal of Pattern Recognition and Artificial Intelligence, 14(05), 675688. doi:10.1142/s021800140000043x

Zhang, Q. V. (2017, March 6). Entrepreneurship growing in Japan, but challenges remain. Retrieved December 14, 2017, from http://news.medill.northwestern.edu/chicago/entrepreneurshipgrowing-in-japan-but-challenges-remain/ 